\title{
Numerical Analysis of Failure Process of Intermittent Single Jointed Rock Mass Based on Potential Energy Dissipating Principle
}

\author{
Wenzhao Chen, Xiqi Liu, Longbin Li \\ Institute of urban construction \\ Nanhua University \\ Hengyang, China \\ liuxiqi@sina.com
}

\begin{abstract}
A rock material biaxial compression test simulation based on the contact constitutive model for brittle rocks is built in this paper by the aid of particle flow code in two dimensions, which is on the basis of parameter sensitivity analysis and analysis by inversion to get the microscopic model parameters. Furthermore, a rock sample with intermittent single joint containing different angle is established on the basis of adaptability, which analyzed new crack initiation in the process of rock in compression, extension, damage and the crack under different joint angle to carry out the whole process, crack number change process by combining the energy dissipation mechanism. It is shown that the extension process of jointed rock mass is essentially driven by energy release of dynamic instability phenomenon caused by the energy dissipation. The destruction form, peak stress and crack number of jointed rock mass are related to joint angle which shows the overall performance: lager the joint angle is, the greater the peak stress of rock mass damage will be, the more the number of rock's crack will be.
\end{abstract}

Keywords-rock material biaxial compression test; particle flow code in two dimensions; crack initiation; crack number

\section{I.INTRODUCTION}

The rock mass encountered in engineering has complex structure, which is often cut by structure face of crack, intercalation and fault. A large number of engineering practice shows that rock slope and underground cavern instability of rock engineering is closely related to the internal development of joint rock mass. The existence of crack has great influence on deformation and strength of rock mass. Thus, it has very important significance for study on jointed rock mass in the process of crack initiation and propagation.

Domestic and foreign scholars have done some research work about crack propagation theory from theoretical and experimental. Cook, Kemeny, Hoek ${ }^{[1-4]}$ according to the theory of fracture machanics did research on rock crack extension under stressful situation. Horii $\mathrm{H}$, Ashby M F, Wang Gengsun, Li Shucai ${ }^{[5-6]}$ studied the linking mechanism of multiple crack under condition of single and biaxial, which points out that the macro damage is mainly related to the crack distribution, lateral pressure and transfixion crack.

\section{DISCRETE ELEMENT MODEL}

Cement mortar is used to simulate fracture rock sample and uniaxial compression test is done in this paper. From Figure 2 we can know that the damage form of this kind of model material has both typical characteristics of shear failure and surface tension split, which can instead of brittle rock mass for its characteristics are similar to brittle rock's failure characteristics under uniaxial compression. Using particle flow code in two dimensions to simulate the biaxial test with a material size of $40 \times 80$ $\mathrm{mm}$, the loading device is simulated with wall (as it's shown in Figure1,2). Model mesoscopic parameters are got through inversion analysis based on parameter sensitivity analysis. From Figure 2,we can easily see that the simulation curve is in good agreement with the test curve, which provide the basis for the following question.

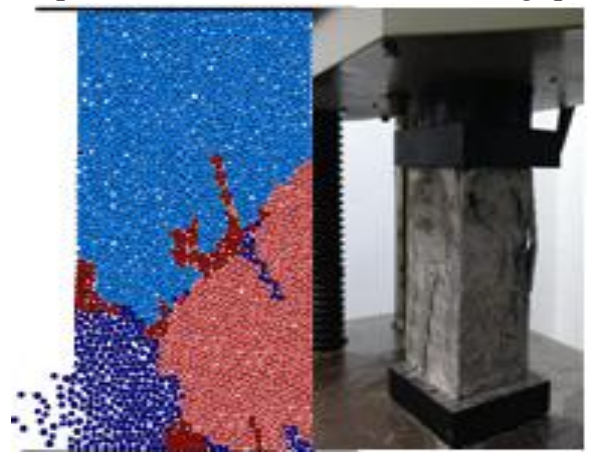

Figure 1. PFC Uniaxial and Uniaxial Test

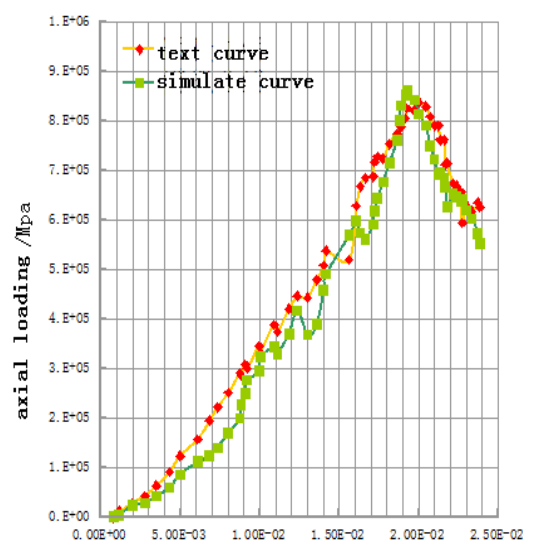

Figure 2. Stress-strain Curve Compression Text 
TABLE I THE PARAMETERS OF ROCK

\begin{tabular}{|c|c|c|c|c|c|c|c|c|c|}
\hline $\begin{array}{c}\text { Rock } \\
\text { mass } \\
\text { parameter }\end{array}$ & $\begin{array}{l}\text { Particle } \\
\text { proporti } \\
\text { on } \\
\left(\mathrm{kgm}^{3}\right. \\
\text { ) }\end{array}$ & $\begin{array}{l}\text { Radius } \\
\mathrm{mm}\end{array}$ & $\begin{array}{l}\text { Void } \\
\text { ratio }\end{array}$ & $\begin{array}{l}\text { Friction } \\
\text { coefficient } \\
\mu\end{array}$ & $\begin{array}{l}\text { Shear } \\
\text { stiffness } \\
\ln (\mathrm{n} m)\end{array}$ & $\begin{array}{l}\text { Normal } \\
\text { stiffness } \\
\ln (\mathrm{nm})\end{array}$ & $\begin{array}{l}\text { Normal } \\
\text { Stiffness } \\
\text { Parallel } \\
\text { bond } \\
\ln (\mathrm{nm})\end{array}$ & $\begin{array}{l}\text { Shear } \\
\text { Stiffness } \\
\text { Parallel } \\
\text { bond } \\
\ln (\mathrm{nm})\end{array}$ & $\begin{array}{l}\text { Viscous } \\
\text { dampin } \\
\mathrm{g} \\
\text { ratio }\end{array}$ \\
\hline $\begin{array}{l}\text { Parameter } \\
\text { values }\end{array}$ & 2600 & $\begin{array}{l}0.03 \sim 0 \\
.05\end{array}$ & 0.08 & 0.25 & $5 \times 10^{7}$ & $1 \times 10^{8}$ & $1 \times 10^{8}$ & $5 \times 10^{7}$ & 0.5 \\
\hline
\end{tabular}

By changing the joint angle $\left(\alpha=15^{\circ}, 30^{\circ}, 45^{\circ}, 60^{\circ}\right.$, $75^{\circ}$ )to design the model of single jointed rock mass under different working conditions, in which the joints are non-consecutive and with a length of $15 \mathrm{~mm}$.

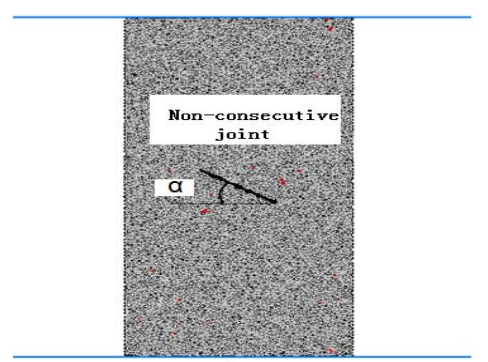

Figure 3. The Sample With Non-consecutive Joint Under Uniaxial Compression

\section{ANALYSIS OF SIMULATION TEST}

A. Analysis of Developing Process of Jointed Rock Mass's Crack Based on Potential Energy Dissipating Principle

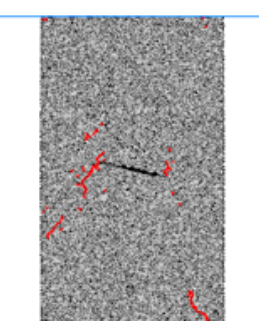

(a) $\mathrm{t}=2000$

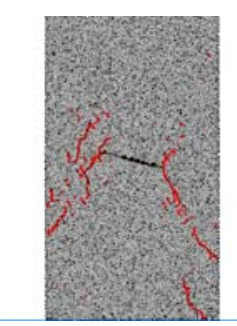

(b) $t=60000$

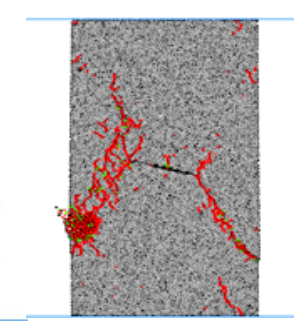

(c) $\mathrm{t}=120000$
Mass When $\alpha=15^{\circ}$

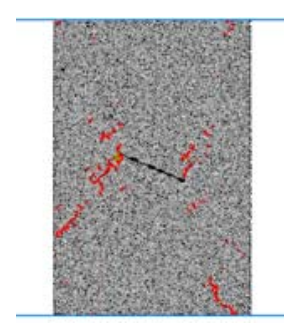

(a) $\mathbf{t}=\mathbf{2 0 0 0 0}$

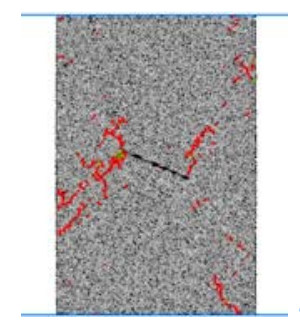

(b) $\mathbf{t}=\mathbf{6 0 0 0 0}$

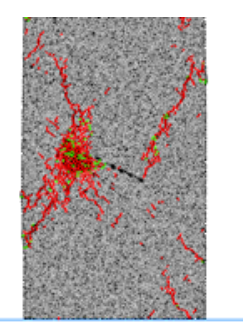

(c)t=120000
Figure 5. Crack Propagation Process of Jointed Rock Mass When $\alpha=30^{\circ}$

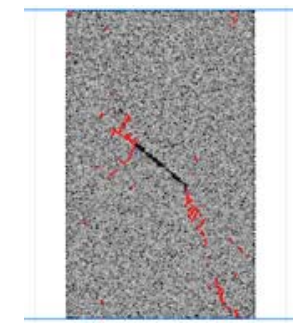

(a) $\mathbf{t}=\mathbf{2 0 0 0 0}$
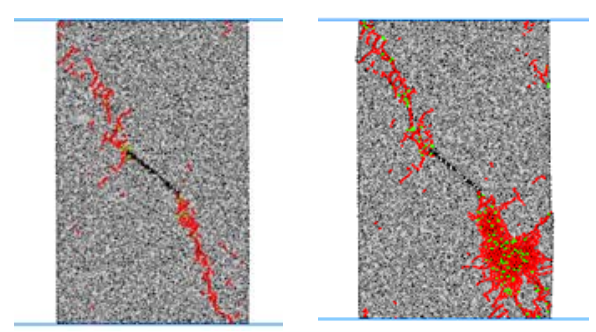

Figure 6. Crack Propagation Process of Jointed Rock Mass When $\alpha=45^{\circ}$

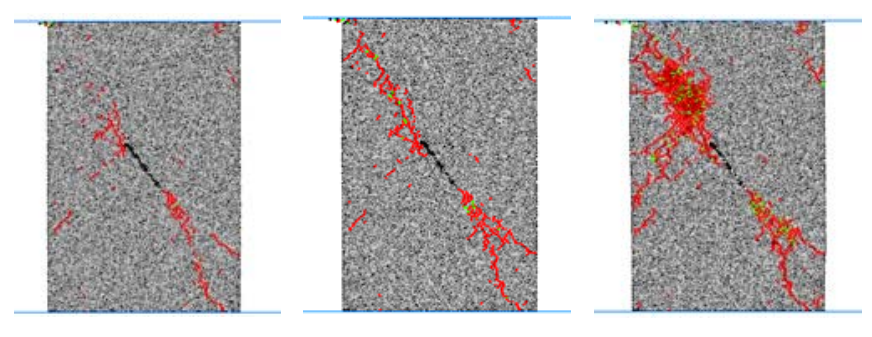

(a) $t=20000$

(b)t $=60000$

(c) $t=120000$

Figure 7. Crack Propagation Process of Jointed Rock Mass When $\alpha=60^{\circ}$

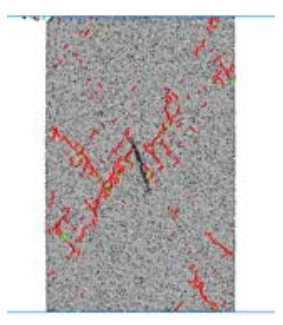

(a) $\mathbf{t}=\mathbf{2 0 0 0 0}$

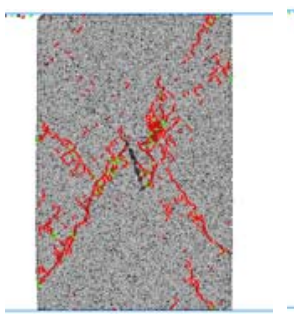

(b) $\mathbf{t}=60000$

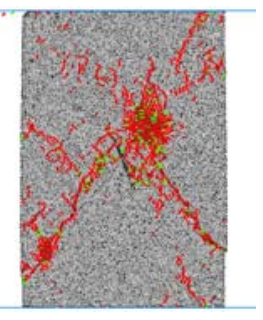

(c)t=120000
Figure 8 . Crack Propagation Process of Jointed Rock Mass When $\alpha=75^{\circ}$

Figure 4-5 show the uniaxial compression test of rocks with different joint angle, which can broadly divided the penetration failure into three types including extensional transfixion damage, compound transfixion damage with tension and shear, shear transfixion damage. As shown in Figure 4-8, for rocks with the same joint angle, crack usually appears in a certain angle at the end and extending direction of joint with the increase of axial pressure, which has the same crack propagation and developing tend with Griffith's strength theory. When jointed rock stressed, the first one to appear at the end of joint is the wing crack, which belongs to tensional crack. It always shows a certain angle initiation ate the end of joint and gradually develops along the path curve, finally in parallel with the direction of maximum principal stress (i,e., the vertical stress).

For rock sample with different joint angle, the extension direction, number and shape of rock's crack have an obvious difference. When the joint angle is small, the crack at tip of joint is mainly secondary cracks and sloping wing crack. Besides, the main form of crack is coplanar secondary crack with the increase of joint angle, which appears obviously when it is $45^{\circ}$ and $60^{\circ}$. 
Therefore, the damage of rock is the result of micro-defects evolution in the process of deformation, which is a self-organizing phenomenon. According to energy dissipating principle, the formation of self organization needs external energy supply and maintains with internal energy dissipation and nonlinear dynamics mechanism.

B. The Stress-strain Relationship and The Changing Process of Crack Number under Different Joint Angle

In Figure 9, the stress-strain curve under different joint angle is shown. It can be seen from the graph that the peak stress presents increasing tend with the increase of joint angle. Figure 11 suggests that there is an approximate linear relationship between the peak stress and joint angle. Figure 10 shows the curve of uniaxial compression crack number under the condition of different joint angle, the number of crack tends to increase with the increase of joint angle. Figure 12 shows a linear relationship between crack's number and joint angle. Besides, at the start of the experiment of uniaxial compression, stress-strain approximately shows a linear relationship. With the increasing of stress, crack inside of jointed rock mass develops rapidly, even a small strain can leads to a sharp expansion of crack.

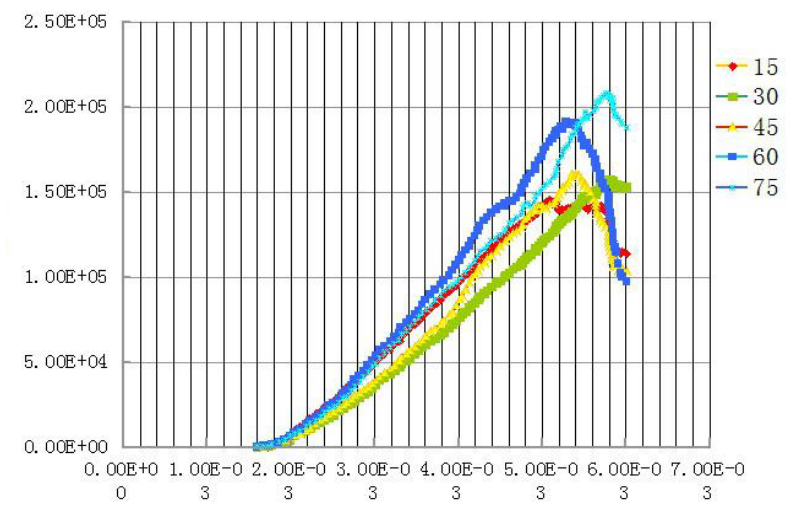

Figure 9. Curve of Stress-strain under Condition of Different Joint Angle

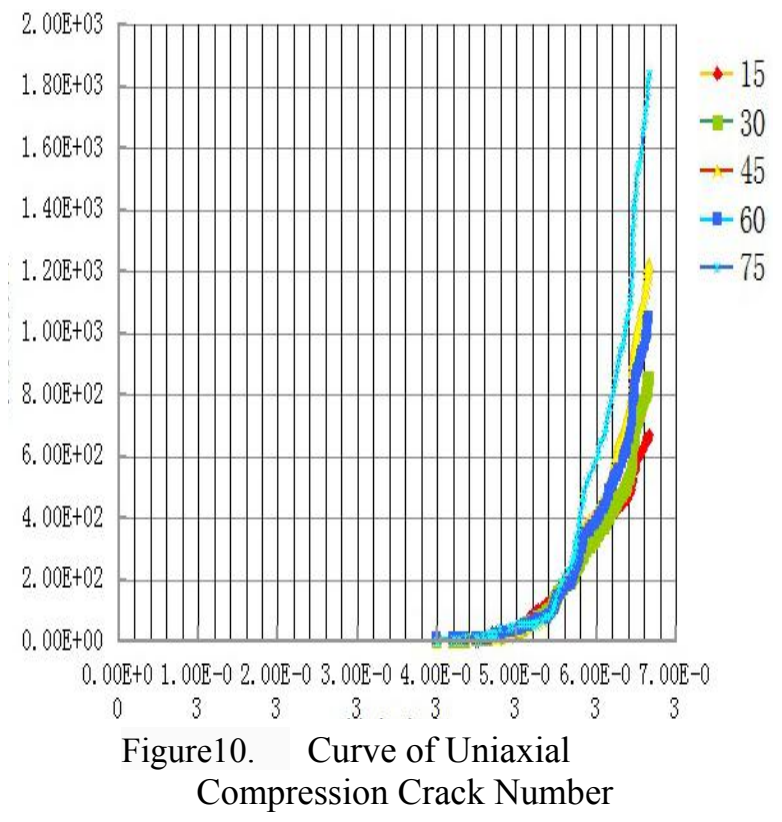

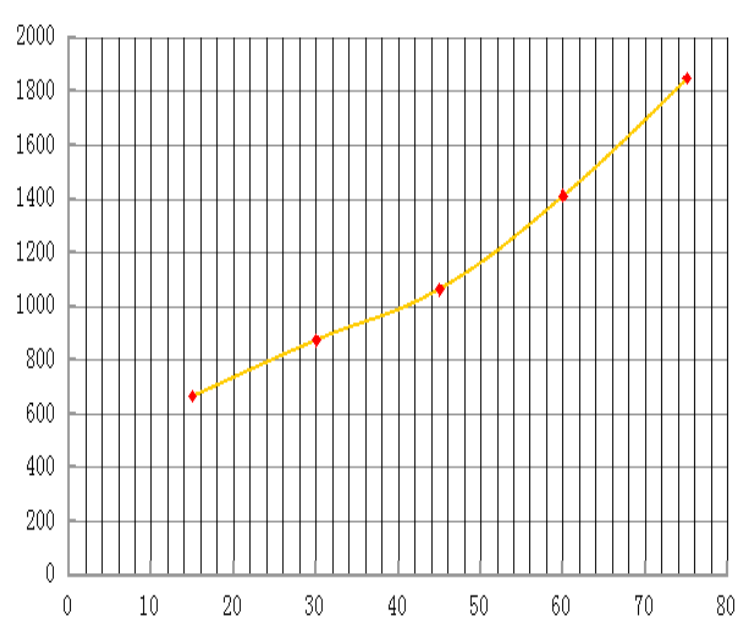

Figure 11. Crack Number Changing with the Joint Angle

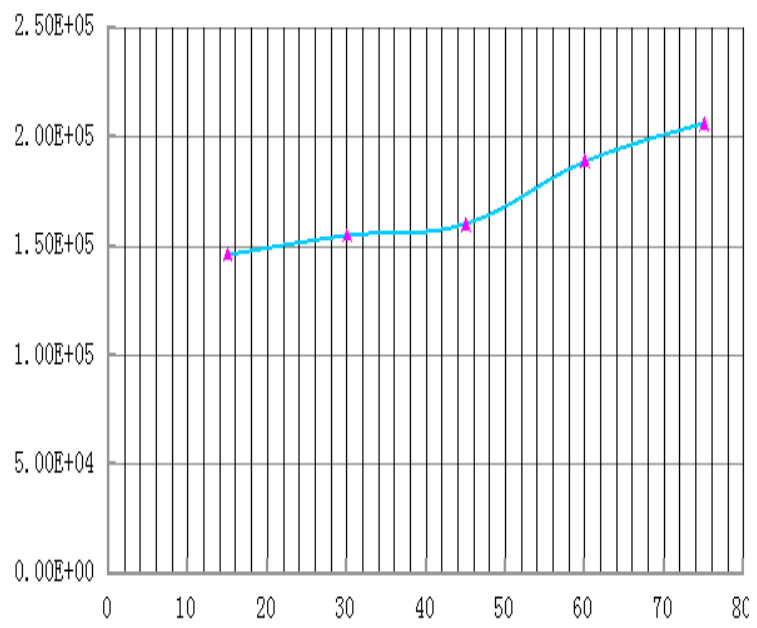

Figure 12. The Axial Peak Stress Changing with Joint Angle

The process of crack propagation inside jointed rock mass is irreversible, which is the product of plastic deformation accumulated to a certain stage. From the point of energy dissipating principle, the input of external energy mainly constitutes the elastic potential energy of rock at the beginning of axial force's loading. Due to the non-uniformity of jointed rock mass, a stress concentration phenomenon will happen at the end of joint, this part of rock mass store more elastic potential energy. With the constantly loading of axial force, rock mass at the end of joint firstly presents plastic deformation, resulting in expansion of rock mass. When the expansion stress is greater than the tensile strength of rock mass, rock cracking phenomenon occurs until the expansion stress is less than the tensile strength. The elastic potential energy stored in rock mass are consumed by surface energy, heating energy and kinetic energy with the propagation of crack. Another part forms the new concentration of stress and energy at the tip of new crack. Thus, the dispersion within the rock micro defect evolution, from the disordered distribution gradually to the orderly development, and form the macroscopic crack, eventually macroscopic crack along a bearing form a big crack cause the overall instability, caused the disaster of 
the rock.

\section{CONCLUSIONS}

Firstly, when the joint angle is small, crack at the tip of joint is mainly secondary and sloping wing crack. With the increase of joint angle, the main form of crack is coplanar secondary cracks.

Secondary, the expansion of jointed rock mass is essentially a dynamic instability phenomenon caused by energy dissipation.

Finally, as the joint angle becoming bigger, the greater the peak stress of rock mass is, the more number of crack will be in uniaxial experiment.

\section{SHORTAGES AND PROSPECTS}

(1)This paper only analyzes the process of uniaxial compression crack propagation under the condition of single joint, which still needs further study on the existence of multiple sets of joints.

(2) The accuracy of particle flow code depends on the model selection of mesoscopic parameters to a large extent. It hard to quantify for there having no definite relationship between mesoscopic parameters and macro-respond. Thus, in order to improve the ability of analyzing practical engineering problems by discrete element simulation, the more analysis of mesoscopic mechanism and macro phenomenon are needed.

\section{REFERENCES}

[1] Cook N G W. The failure of rock[J].Int. J. Rock Mech. Min. Sci.,1965,21(2):389-403.

[2] Kemeny J, Cook N G W. Effective Moduli No-linear Deformation and Strength of a Cracked Elastic Solid[J].Int. J. Rock Mechanics. Min. Sci. \& Geomech. Abstr, 1986,23(2):107-118.

[3] Kemeny J,Cook N G W. Micromechanics of Deformation in Rock[M]. In: Toughening Mechanism in Quasi-Britt le Materials, Kluwer Academic Publi shers, Netherlands, 1991.

[4] Hoek E, Bieniawski Z T. Brittle fracture propagation in rock under compression [J]. Int. J.Fract., 1965,1:137-155.

[5] Hoek E, Brown E T. Underground excavations in rock [M], London: Elserier Press, 1980:105-106.

[6] Horii H, Nemat-Nasser S. Brittle failure in Compression: splitting and brittle-ductile transition[J]. Philosophical Transactions of the Royal Society of London,Series A, 1986,337 374

[7] Ashby M F, Hallam S D. The failure of brittle solids containing small cracks under compressive stress states[J]. Acta Metall,1986,34(3): 497 510

[8] Gengsun Wang. Mechanism and strength of cracked materials under uniaxial compression failure $[\mathrm{J}]$. Rock and soil mechanics, 1992,13(4)

[9] Shucai Li, Weishen Zhu. Fracture damage mechanism of discontinuous jointed rock mass under the state of complex stress and its application[J]. Journal of rock mechanics and engineering, 1999,18(2): 142 146.

[10] C.H. Park, A.Bobet. Crack initiation, propagation and coalescence from frictional flaws in uniaxial compression[J]. Engineering Fracture Mechanics, 2010, 77: 2727-2748.

[11] Dongyan Liu,Study on acoustic emission characters of failure of fissure rock on compression[J].Underground space1998(4):9-19 